\title{
DEMOCRACIA E POBREZA EM PESQUISAS BRASILEIRAS SOBRE EDUCAÇÃO LITERÁRIA*
}

\author{
DEMOCRACY AND POVERTY IN BRAZILIAN LITERARY \\ EDUCATION RESEARCH*
}

\author{
Maria Amélia DALVI**
}

\begin{abstract}
Resumo: Este artigo dedica-se à presença/ausência do debate sobre democracia e pobreza nos recentes estudos desenvolvidos em programas de pós-graduação stricto-sensu brasileiros, devotados à Educação Literária - aqui entendida, com Candido (1995), como um direito. Trata-se de um trabalho metaintelectual, desenvolvido sob a perspectiva materialista histórica e dialética; mapeia ocorrências, nos estudos focalizados, de termos-chave atinentes ao recorte, evidenciando que a tematização da singularidade, da individualidade e da particularidade é muito mais recorrente, e questiona tais dados. A partir de tal constatação, propõe-se uma reflexão a respeito da dimensão ético-política dos estudos científicos avançados desenvolvidos no país no campo.
\end{abstract}

Palavras-chave: Democracia. Pobreza. Pós-Graduação Stricto-Sensu. Educação literária.

Abstract: This paper addresses the presence/absence of debate on democracy and poverty in recent studies developed in Brazilian graduate programs devoted to literary education, which is understood as a right (CANDIDO, 1995). It is a meta-intellectual work, developed from the historical and dialectical materialism perspective; it maps previous research for related key terms and shows that the thematization of singularity, individuality and particularity is much more recurrent than social and collective realities, and also questions this data. From this finding, this paper proposes a reflection on the ethical-political dimension of the advanced scientific studies carried out in Brazil in this area.

Keywords: Democracy. Poverty. Graduate Studies. Literary Education.

\section{Considerações iniciais}

As pesquisas sobre educação literária vêm aumentando substancialmente ${ }^{1}$ na realidade acadêmica brasileira, provavelmente como desdobramento de um conjunto de fatores, dentre os quais: a) a reorientação da Coordenação de Aperfeiçoamento de Pessoal de Nível Superior (Capes), visando dedicar-se não apenas à pesquisa científica e ao ensino superior, mas também a questões e problemas concernentes à educação básica ${ }^{2}$; b) a criação e a ampliação dos

\footnotetext{
* Trata-se de resultado parcial da pesquisa "A constituição da educação literária no Brasil contemporâneo" registro 8990/2018 - PRPPG/Ufes.

** Professora dos Programas de Pós-Gradução em Educação e em Letras da Universidade Federal do Espírito Santo (UFES). Doutora em Educação pela UFES. E-mail: dalvimariaamelia@gmail.com.

${ }^{1}$ Como será discutido adiante, de um conjunto de 72 trabalhos disponíveis no Catálogo de Teses e Dissertações da Coordenação de Aperfeiçoamento de Pessoal de Nível Superior (Capes), localizados a partir da palavra-chave "educação literária"; 50 se concentram nos anos de 2017 e 2018.

${ }^{2}$ Por exemplo, em artigo assinado por Jorge Guimarães, ex-presidente da Coordenação de Aperfeiçoamento de Pessoal de Nível Superior (Capes), lemos que: “[...] uma importante lacuna [...] persistia na Capes [...]: o apoio deficiente às carências da Educação Básica. Passados 56 anos desde a criação da Capes, [...] cria-se assim a Nova
} 
mestrados profissionais em Educação e em Ensino, devotados à formação continuada de profissionais atuantes das redes públicas de educação básica ${ }^{3}$; c) as vicissitudes de políticas públicas para o livro, a leitura e a literatura (ROSA; ODDONE, 2006; BELO, 2016; DALVI, 2018, 2019; SALA, 2018); e d) a oficialização de uma Base Nacional Comum Curricular ${ }^{4}$.

Face a isso, levando em conta o contexto contemporâneo - em que o país tem experienciado graves retrocessos tanto no combate à desigualdade socioeconômica (NERI, 2019) quanto no fortalecimento das instituições e práticas democráticas ${ }^{5}$ (PEREZ-LINAN, 2018) -, este artigo dedica-se à presença/ausência do debate sobre democracia e pobreza nos estudos científicos desenvolvidos em programas de pós-graduação stricto-sensu nas áreas de Educação e Letras, devotados à Educação Literária. Tal educação, embora não seja realizada

Capes, que passa a induzir e fomentar também a formação inicial e continuada de professores para a Educação Básica" (grifos nossos). Disponível em: http://www.capes.gov.br/acessoainformacao/informacoesclassificadas/57-salaimprensa/artigos/4721-a-capes-e-a-educacao-basica. Acesso em: 20 ago. 2019. Como desdobramento desta nova política, na aba dedicada à Diretoria de Formação de Profissionais da Educação Básica no sítio eletrônico da Capes, lê-se que a diretoria em questão atua em duas linhas de ação: "fomento a projetos de estudos, pesquisas e inovação, desenvolvendo um conjunto articulado de programas voltados para a valorização do magistério"; afora isso, a mesma diretoria apresenta como uma de suas vertentes a "integração entre pósgraduação, formação de professores e escola básica”. Disponível em: https://www.capes.gov.br/educacaobasica/prodocencia. Acesso em: 20 ago. 2019.

${ }^{3}$ O sítio eletrônico da Capes, em texto datado de janeiro de 2018, informa que: "Os Programas de Mestrado Profissional para Qualificação de Professores da Rede Pública de Educação Básica - ProEB tem [sic] por objetivo a formação continuada stricto sensu dos professores em exercício na rede pública de educação básica, em conformidade com a política do Ministério da Educação - MEC, mediante apoio às instituições de ensino superior (IES) ou rede de instituições associadas do País, responsáveis pela implantação e execução de cursos com áreas de concentração e temáticas vinculadas diretamente à melhoria da Educação Básica. O apoio da CAPES dar-se-á mediante a concessão de bolsas e fomento aos cursos de Mestrado Profissional do ProEB, nas modalidades presencial e a distância, no âmbito do Sistema Universidade Aberta do Brasil - UAB [...]. O PROEB tem como finalidade a melhoria da qualidade do ensino nas escolas da Educação Básica Pública Brasileira”. Disponível em: https://www.capes.gov.br/educacao-a-distancia/proeb. Acesso em 20 ago. 2019.

${ }^{4}$ De acordo com o sítio eletrônico do Ministério da Educação (MEC), "A Base Nacional Comum Curricular (BNCC) é um documento de caráter normativo que define o conjunto orgânico e progressivo de aprendizagens essenciais que todos os alunos devem desenvolver ao longo das etapas e modalidades da Educação Básica". Ainda de acordo com o sítio eletrônico do MEC, "Conforme definido na Lei de Diretrizes e Bases da Educação Nacional (LDB, Lei $\mathrm{n}^{\circ}$ 9.394/1996), a Base deve nortear os currículos dos sistemas e redes de ensino das Unidades Federativas, como também as propostas pedagógicas de todas as escolas públicas e privadas de Educação Infantil, Ensino Fundamental e Ensino Médio, em todo o Brasil". Disponível em: <http://basenacionalcomum.mec.gov.br/ >. Acesso em: 20 ago. 2019.

${ }^{5}$ De acordo com notícia publicada no jornal O Globo, "Um terço da população mundial [...] está sob ameaça de retrocesso democrático. O estudo apontando "tendências inquietantes" em 24 países foi revelado na semana passada [...] e o Brasil é o primeiro entre as seis nações nas quais houve recuo na democracia entre 2015 e 2017. [...] A conclusão é do segundo relatório anual Variedades da Democracia (V-Dem), elaborado por mais de três mil peritos em ciências sociais de 177 países e liderados por um grupo da Universidade de Gotemburgo, na Suécia. O estudo também criou outros rankings, entre eles os das nações mais democráticas, onde o Brasil é o $56^{\circ}$ entre 201 países". Disponível em: < https://oglobo.globo.com/mundo/estudo-indica-que-13-da-populacao-vive-sob-riscode-retrocesso-democratico-23074380 >. Acesso em: 18 ago. 2019. Textualmente, o relatório anual V-Dem informa que "24 countries are now severely affected by what is established as a 'third wave of autocratization'. These countries include Brazil, India, the United States, as well as several Eastern European countries" (grifos nossos). Disponível em: < https://www.v-dem.net/en/news/democracy-facing-global-challenges-v-dem-annualdemocracy-report-2019/ >. Acesso em 18 ago. 2019. 
exclusivamente pela escolarização, encontra, nas instituições formais, tais como escolas e universidades, um lócus privilegiado de guarda e de transmissão/assimilação do conhecimento literário e de fomento às experiências literárias significativas. Tais conhecimentos e experiências são aqui entendidas, com Candido (1995) e Dalvi (2018), como um "direito incompressível”, ou seja, que não poderia ser de modo algum renegado ou suprimido, sob pena de mutilação do propósito de formação integral da personalidade humana. Um tal processo omnilateral - para o qual a dimensão literária seria incontornável, sob pena de mutilação da própria humanidade do ser humano -, a ser desenvolvido, principalmente, a partir do processo educativo e educacional, aqui é entendido como daquele tipo que:

[...] tenha possibilidades concretas de produzir uma pessoa de pensamentos, com autonomia intelectual para analisar a realidade valendo-se de instrumentos conceituais em suas formas mais elaboradas; uma pessoa de sentimentos, que se forme sensível ao conjunto dos seres humanos e que possua senso de justiça, revoltando-se contra arbitrariedades que se pratique contra qualquer membro do gênero humano. Que culmine na produção de uma pessoa da práxis, que compreenda as contradições sociais existentes no processo de produção e reprodução da sociedade, que se engaje na luta pela implementação de uma sociedade livre da dominação e da opressão. (MARTINS, ABRANTES, FACCI, 2016, p. 3-4).

Dessa feita, o trabalho aqui sistematizado pode ser identificado como de natureza metaintelectual, sendo realizado sob a perspectiva da Filosofia Enunciativo-Discursiva de base materialista histórica e dialética. Mapeia e contrasta ocorrências de termos-chave para o estudo proposto, levando em conta: a) o contexto de sua produção e circulação, brevemente delineado nos parágrafos e notas já apresentados ao leitor; e b) a não-pessoalização dos estudos identificados, inserindo-os, antes, como evidências a partir das quais se pode perquirir um dado momento histórico-cultural. A partir disso, propõe-se uma metarreflexão a respeito da dimensão ético-política dos estudos científicos avançados (em nível de doutorado) desenvolvidos no país, no campo da Educação Literária.

Ao realizar uma busca no Catálogo de Teses e Dissertações da Coordenação de Aperfeiçoamento de Pessoal de Nível Superior (Capes) pelo termo "Educação Literária", retornam 72 resultados $^{6}$, dos quais 37 dissertações de mestrado acadêmico, 25 teses de doutorado e 10 trabalhos (de diferentes gêneros, também cognominados "produtos finais") realizados dentro de cursos de mestrado profissional. Há forte concentração (50 dos 72 resultados) nos anos de 2017 e 2018 (coetânea e posteriormente, portanto, ao processo de finalização da Base Nacional Comum Curricular).

\footnotetext{
${ }^{6}$ A busca foi atualizada até o dia 24 de abril de 2019, às $9 \mathrm{~h}$ da manhã, por meio do seguinte endereço: https://catalogodeteses.capes.gov.br/catalogo-teses/.
} 
Restringindo a busca aos anos de 2017 e 2018 (anos de maior concentração de produção) e ao nível de doutorado (supostamente, de maior amadurecimento intelectual dos autores, maior aprofundamento das discussões e mais provável teor de originalidade - além de terem sido desenvolvidos em programas de pós-graduação idealmente mais amadurecidos, com grupos e linhas de pesquisa mais consolidados), restam seis trabalhos, sendo quatro na área de conhecimento "Educação" e dois na subárea de conhecimento "Letras". Entendemos a representatividade do conjunto não apenas em face de serem trabalhos mais recentes, concentrados no período de maior produtividade do campo e realizados no maior nível de formação acadêmico-científica, mas também por, matematicamente, corresponderem a 1/12 do total de trabalhos produzidos em todo o acervo do Catálogo de Teses e Dissertações da Capes, sem restrição de recorte temporal, sob a expressão chave "Educação Literária". Esse é, pois, o corpus privilegiado para a análise e reflexão aqui desenvolvida.

Os dados são hauridos a esse conjunto representativo com base nos seguintes critérios: a) instituições em que foram desenvolvidos e sua região de localização; b) extensão dos trabalhos; c) diversidade de temas contemplados; d) nível e modalidade de educação contemplados; e) ocorrências quantitativas (analisadas contextualmente) de palavras-chave para o estudo e seus cognatos.

Estudando sistematicamente os conhecimentos que vêm sendo publicados no tocante à "Educação Literária", e antecipando parcialmente as conclusões desse estudo, faz-se premente delinear uma questão: haja vista a baixa presença de termos relacionados à pobreza e à democracia como processo social coletivo, e a alta incidência de termos relacionados à individualidade, à singularidade e à subjetividade, haveria uma tendência à fetichização (DUARTE, 2012) da educação literária nos estudos (porque desentranhada da realidade histórico-social ampla), na produção de vanguarda do campo (ou seja, aquela feita por doutores em formação - ou seja, especialistas em Educação Literária -, em programas de pós-graduação consolidados)?

Fazemos a pergunta não com o intuito de renegar ou criticar qualquer suposto centramento da abordagem na dimensão individual, singular e subjetiva, tampouco recaindo em uma polarização mecanicista e ingênua (como se houvesse necessariamente uma dicotomia entre as diferentes dimensões da reflexão sobre educação literária); o objetivo é outro: temos em vista compreender metarreflexivamente - ou seja, "desde dentro" - a atualidade de um campo de pesquisa emergente no Brasil. 
A respeito da importância desse tipo de movimento, Dalvi, em artigo que estudou a pesquisa avançada na interface Literatura e Infância nas áreas de Educação e Letras, defende que:

[...] coligir as linhas de força das pesquisas em questão seria um dos modos de nos colocar diante da vida acadêmica e, portanto, social, interrogando-nos não só acerca dos objetos, estatutos, corpora, sujeitos, metodologias e suportes teóricos, mas, principalmente, aventando questões para o conjunto de dados produzidos a partir da consulta conjunta às teses de doutorado publicadas integralmente em portais oficiais, no escopo apresentado.

Dito de outro modo, parece-nos que, aos pesquisadores [...] talvez coubesse, neste momento, conhecer, de um outro lugar de interrogação (e, portanto, de um lugar novo, difícil, imprevisto), o que vem sendo produzido na área: em vez de tomar as pesquisas recentes como fontes - como vem sendo sistematicamente feito, com muita competência, por múltiplos sujeitos -, toma-las também como objetos.

Para tanto, nessa mudança de direção, faz- se necessário lembrar que Edward Said (2005) advoga o comportamento de amador para o intelectual e evoca, em sua argumentação, o pensamento de George Steiner, que propunha uma existência "deliberadamente inoportuna" [...] - porque aquele que "se mete no que não é da sua conta", é "amador" e "inoportuno" parece, também, "estranho" (FREUD, 1996), ou seja: obriga a desestruturar e transformar o já dado. (2015, p. 154-155).

Portanto, os dados e reflexões aqui sintetizados não se configurariam como uma crítica a trabalhos específicos (autores, teses, orientadores, bancas, programas etc.), mas como uma metacrítica a nós, conjuntamente, como estudiosos formadores de pessoal de nível superior em um determinado segmento de estudos, que temos uma responsabilidade ético-política com o exercício contínuo da reflexão.

Talvez, a convocação/provocação aqui delineada tenha nascido da identificação de uma tendência no processo de constituição do campo de estudos em "Educação Literária" no Brasil, como desdobramento de um processo social macro que tem seu nascedouro na historicidade econômico-social (GARCIA; COUTINHO, 2004), com raízes muito mais fundas que as particularidades da Educação, da Literatura, ou de sua interface - aludimos, especificamente, ao sistema econômico-social responsável por um certo modo de produção e um certo padrão de relacionamentos intersubjetivas, com desdobramentos inequívocos na formação do psiquismo individual e coletivo.

Evidentemente, nos limites de um artigo acadêmico, é impossível exaurir as questões que nos inquietam - é impossível mesmo apresentá-las, situá-las e desenvolvê-las adequadamente. O intuito, portanto, é principalmente o de mobilizar o pensamento, a curiosidade e os afetos em direção ao (auto)questionamento a partir dos dados produzidos por meio da consideração do corpus, como um convite para que nos entreguemos ao problema não isoladamente, mas 
partilhando-o entre nós, corresponsabilizando-nos pelas respostas que o momento histórico em que vivemos exige e exigirá de nós. Afinal, a questão incômoda que aqui nos move é: que lugar nós, pesquisadores do campo emergente denominado como "Educação Literária", temos reservado em nossos trabalhos à discussão da pobreza e da democracia, em um contexto turbulento e eivado de retrocessos, conforme os dados de pesquisa mencionados anteriormente (NERI, 2019; PEREZ-LINAN, 2018)?

\section{Pesquisas sobre Educação Literária}

O conjunto de teses resultante da filtragem empreendida a partir dos critérios apresentados nas considerações iniciais é o seguinte:

Quadro 01 - Síntese das teses que constituem o corpus $^{7}$

BATISTA, J. D. A escrita literária e a Olimpíada de Língua Portuguesa “Escrevendo o Futuro": memórias de uma professora. 18/12/2017. 267 f. Tese de Doutorado (Letras). Universidade Federal do Espírito Santo, 2017. CAMASMIE, V. de A. Aulas de Literatura do Ensino Fundamental I do Colégio Pedro II - campus Humaitá. 08/12/2017. 249 f. Tese de Doutorado (Educação). Universidade Federal do Rio de Janeiro, 2017.

CAVALCANTE, R. de C. Práticas para educação literária: a formação docente na licenciatura em Letras em uma instituição pública do sul do Brasil. 30/01/2018. 158 f. Tese de Doutorado (Letras). Universidade Federal do Rio Grande do Sul, 2018.

QUEIROZ, H. A. A poesia em territórios improváveis: jovens de periferia em cena. 02/05/2017. 246 f. Tese de Doutorado (Educação). Universidade Federal do Rio de Janeiro, 2017.

SANTOS, O. M. S. dos. A Literatura e a escola: um estudo sobre modelos de educação literária no ensino médio em escolas públicas de Salvador (BA). 28/04/2017. 323 f. Tese de Doutorado (Educação). Universidade Estadual de Campinas, 2017.

SPENGLER, M. L. P. Alçando voos entre livros de imagens: o acervo do PNBE para a Educação Infantil. 22/03/2017. 213 f. Tese de Doutorado (Educação). Universidade Federal de Santa Catarina, 2017.

Fonte: <https://catalogodeteses.capes.gov.br/catalogo-teses/>. Acesso em 24 abr. 2019.

Como se pode ver, as teses que constituem o corpus de análise estão distribuídas entre cinco instituições no país: Universidade Federal do Rio de Janeiro, com dois trabalhos; e Universidade Estadual de Campinas, Universidade Federal de Santa Catarina, Universidade Federal do Espírito Santo e Universidade Federal do Rio Grande do Sul, com um trabalho cada. Como se nota, os trabalhos estão concentrados nas regiões Sul e Sudeste do país, que, historicamente, sediam a maior parte dos programas de pós-graduação stricto sensu, incluindo os mais bem avaliados pelo órgão federal responsável. Ou seja, em se tratando de programas consolidados e repetidamente bem avaliados, fica reforçado o argumento de que se tratam de trabalhos muito representativos do que de mais avançado vem sendo produzido.

\footnotetext{
${ }^{7}$ Catálogo de Teses e Dissertações da Capes, a partir da palavra-chave "Educação Literária"; filtragem nos anos de 2017 e 2018, teses de doutorado desenvolvidas em programas de pós-graduação na área de Educação e na subárea de Letras. A busca foi atualizada até o dia 24 de abril de 2019, às 9h da manhã. Quadro organizado pela autora.
} 
O número de folhas dos trabalhos fica entre 158 e 323, com média de 242,6 folhas - o que evidencia que se trata de trabalhos alentados, ao menos do ponto de vista da extensão textual. Esse conjunto de teses aponta uma vitalidade e uma diversidade, elementos fundamentais à constituição de um campo de pesquisa (no caso, "Educação Literária") no Brasil: estão em pauta cenas periféricas, educação poética, livros de imagens, acervos escolares, programas público-privados, memórias docentes, escrita literária, modelos de educação literária, práticas escolares, formação de professores. Além disso, os trabalhos perpassam diferentes segmentos, a saber, Educação Infantil, Anos Iniciais do Ensino Fundamental, Anos Finais do Ensino Fundamental, Ensino Médio e Ensino Superior.

A análise dos resumos evidencia também a diversidade de pressupostos teóricometodológicos, e diversas sistemáticas de produção/coleta de dados, categorização, análise/síntese e crítica. Ficando restritos à fundamentação teórico-metodológica (como indício de todo esse conjunto possível de elementos de análise), é perceptível a diversidade de autores ${ }^{8}$ - e, portanto, de tendências ou filiações - aos quais o corpus constituído para este estudo alude:

a) Batista (2017) elege Roger Chartier, Catherine Tauveron, Elisa Dalla-Bona, João Wanderley Geraldi, Luci Calkins e Lev Vigotski;

b) Camasmie (2017) define como autores estruturantes de seu referencial teórico Rildo Cosson e Graça Paulino, Teresa Colomer, Lev Vigotski, Jorge Larrosa, Walter Benjamin, Mikhail Bakhtin, Ciça Fittipaldi, Luiz Percival Leme Britto, Vanessa Camasmie e Elisabeth d'Angelo Serra; e

c) Santos (2017) agencia como autores centrais de seu referencial Marisa Lajolo, Regina Zilberman, Bárbara Freitag, Márcia Abreu, Antônio Gomes Batista, Ezequiel Theodoro da Silva, Roxane Rojo, Maria José Coracini, Rildo Cosson, Célia Cassiano e Cyana Lahy-Dios nos três conjuntos, é patente que se situam em tradições epistemológicas muito distintas entre si, mesmo em relação a noções-chave para o campo, tais como linguagem, ensinoaprendizagem, formação e desenvolvimento humano, literatura, leitura;

d) Cavalcante (2018) assume como referenciais centrais Antonio Candido, Cyana LeahyDios, Teresa Colomer, Mikhail Bakhtin, João Wanderley Geraldi e Tzvetán Todorov replicando, igualmente, o procedimento já identificado e comentado anteriormente, embora com uma tendência um pouco maior de aproximação de autores em sua maioria interessados na crítica material às relações entre literatura, educação e sociedade;

\footnotetext{
${ }^{8}$ Os autores que constituem o referencial teórico-metodológico do conjunto de teses em estudo são citados na mesma ordem em que aparecem nos respectivos resumos ou, internamente, no corpo da tese estudada.
} 
e) Queiroz (2017) toma como referenciais autores como Mikhail Bakhtin, Antonio Candido, Roger Chartier, Teresa Colomer, Patrícia Corsino, Octavio Paz, Michèle Petit, Roxane Rojo, Bryan Street, Bernard Lahire, Paul Zumthor, Miriam Abramovay, Rosa Maria Macêdo, Maria Luiza Magalhães Oswald, Celecina Veras Sales e Beatriz Sarlo - provenientes não apenas de tradições diferentes, mas também de campos e áreas extremamente diversificados e em patamares de seu percurso intelectual (e, portanto, de consolidação do próprio arcabouço conceitual/instrumental) muito distintos;

f) Splenger (2017) delineia o corpo de referências centrais em torno dos nomes de Luís Camargo, Graça Lima, Ana Margarida Ramos, Maria Nikolajeva, Scott [não referenciado], Sophie Van der Linden, Nelly Novaes Coelho, Regina Zilberman, Peter Hunt, Eliane Debus, Mônica Correia Baptista, Yolanda Reyes, Rildo Cosson, Blanca-Ana Rechou, Aparecida Paiva e Célia Fernandes - aqui temos uma diferença em relação às teses anteriores, pois a autora optou por erigir também depoimentos e memórias de criadores (ilustradores, artistas do livro infantil etc.) à condição de produção teórica, igualando na organização de seu referencial central pesquisadores especializados e artistas.

Ou seja, o campo de pesquisa Educação Literária, em constituição, felizmente evidencia uma diversidade de autores e tradições e abordagens epistemológicas e ontológicas. Porém, parece, em uma primeira observação, haver pouca atenção ou pouca rigidez consoante à compatibilização no tocante aos fundamentos dessas mesmas tradições e abordagens, ao serem assumidas como estruturantes para a constituição do embasamento teórico-metodológico das pesquisas.

Em uma visada exploratória, talvez seja pertinente supor que esse dado sinaliza que os autores de referência são escolhidos principalmente em relação aos temas ou questões que estudam, e não com base em sua afinidade ou crítica a dada corrente ou tendência epistemológica. Isso talvez seja um mérito do campo, muito embora haja o risco de essa aposta coletiva avançar em direção a uma inconsistência, com pouca contundência crítico-analítica o que nos eximimo de levar adiante nos limites deste diminuto texto.

Tais constatações mostram que o cenário tem se transformado muito rapidamente, em comparação ao período entre 2011 a 2016, quando foi publicada uma série de estudos históricos, estados-da-arte e alguns ensaios mapeando o campo; sua leitura explícita ou à contrapelo mobiliza posicionamentos em favor de uma constituição mais efetiva, orgânica e tática do campo de estudos (DALVI et al., 2011; DALVI, 2011; DALVI, REZENDE, 2012; 
GINZBURG, 2012; DALVI, 2013; MORTATTI, 2014; ANTUNES, 2015; DALVI, 2015; DIAS, OLIVEIRA, 2015; ELISBON, VALTÃO, 2015; ZAMBRANO, 2015; SILVA, 2016).

Sistematizando conclusões desse conjunto de trabalhos mencionados no parágrafo acima, fica patente que, à sua época de publicação:

a) os cursos de licenciatura em Letras e Pedagogia concedem um espaço muito limitado à discussão sobre a educação literária de professores e sobre as possibilidades didáticas para o trabalho com os textos e sistemas literários na educação básica, e são raros os estudos de campo e com sujeitos empíricos, que pensam a educação literária face à análise e problematização de políticas públicas de cultura e educação;

b) os programas de pós-graduação pelo país normalmente têm professores-orientadores isolados pensando a educação literária, e as bancas de avaliação raras vezes contam com especialistas com pesquisas em curso nessa interface - exceto em casos muito particulares de instituições com grupos de pesquisa já consolidados; mesmo os grupos de pesquisa, majoritariamente, estão em processo de constituição nos últimos cinco anos, o que pode ser um tempo ainda insuficiente para seu amadurecimento e pleno funcionamento;

c) as orientações oficiais são pouco claras e há escassa consistência teórico-metodológica, com definições imprecisas e mesmo conflitantes entre os diferentes documentos e com minimização ou desconsideração pelas condições materiais objetivas em que se desenvolvem as práticas de ensino-aprendizagem;

d) as revisões bibliográficas presentes nos estudos dialogam pouco com as teses e dissertações e com os artigos em periódico, de modo que as referências mais frequentemente citadas (fundamentalmente, livros e autores clássicos) se repetem à exaustão, ignorando o conhecimento mais atualizado produzido a partir da pesquisa empírica/de campo;

e) a dimensão histórica e política do processo de constituição da educação escolar e dos currículos escolares é secundarizada nos estudos e, por isso mesmo, as contextualizações sociológicas profundas são raras, bem como é minimizado o entendimento do campo literário como intimamente vinculado à concepção de sociedade e linguagem e, assim, à disputa por hegemonia, poder e prestígio;

f) os estudos em Educação Literária sofrem uma desvalorização e desprestígio no núcleo duro constitutivo da área de Letras e Linguística (possivelmente como decorrência do fato de que a relação com infância e com escola básica faz emergir aquilo que ficou consignado nos estudos especializados como "feminização" do magistério); 
g) entre os periódicos da área de Letras e Linguística, nenhum ou quase nenhum era especializado na interface Literatura e Educação, e os estudos publicados, muitas vezes, se restringiam a relatos de experiência (com análises pouco contundentes e frequentemente submissas aos ditames de documentos oficiais);

h) as traduções de clássicos e de obras recentes sobre Educação Literária e Didática da Literatura (especialmente latino-americanos) ainda são escassas e circulam pouco; e

i) a expansão da ideologia (neo)liberal e sua contraparte teórica - com a ascensão de perspectivas que apostam na individualidade, em uma falsa liberdade (como identificação à legitimidade de um projeto ególatra) e na corrosão de projetos coletivos - desvalorizaram e desacreditaram a perspectiva de um processo de formação humana omnilateral, universal e coletivo, que vise à transformação da sociedade em direção a maior equanimidade.

À luz dessa sistematização dos estudos publicados entre 2011-2016 e daqueles elementos mencionados no primeiro parágrafo deste texto (quando apresentamos indícios sobre o aumento vertiginoso dos estudos no campo), fica patente que o campo ao mesmo tempo que se movimenta (por exemplo, superando algumas das lacunas constatadas), conserva algumas suscetibilidades. Porém, a indagação fulcral, aqui, não é sobre a constituição da área como um todo, mas sobre como a pobreza e a democracia têm ou não sido abordadas nas pesquisas avançadas recentes nesse campo em constituição. Por isso, passamos ao item seguinte.

\section{Dados para o diálogo}

Haveria, é certo, muitos caminhos para indagar ao conjunto de seis teses de doutorado produzidas no Brasil nos anos de 2017 e 2018, indexadas pela expressão-chave "Educação Literária", visando responder à questão central formulada. Poder-se-ia, como já sinalizamos anteriormente, indagar os fundamentos ontológicos e epistemológicos dos referenciais teóricometodológicas dos estudos; poder-se-ia analisar o conteúdo desde a proposição de métodos de produção/coleta e organização dos dados; poder-se-ia comparar as conclusões dos estudos. Porém, tudo isso exigiria uma nova tese - e os limites deste trabalho são bem mais modestos.

Desse modo, foi definido um rol de palavras-chave de interesse para o nosso estudo, a partir das quais foram feitas buscas no interior dos documentos eletrônicos em questão, localizados a partir do Catálogo de Teses da Capes. Não se trata da localização de palavraschave indicadas pelos autores das teses que constituem o corpus documental em estudo, mas de palavras-chave por nós definidas, a serem localizadas no interior dos trabalhos localizados por meio da leitura e de recursos eletrônicos inerentes aos processadores digitais de arquivos 
textuais. A opção por trabalhar com palavras-chave, definidas em função do interesse de nosso estudo, deve-se à constatação de estudiosos tais como Borba, Van der Lann e Chini (2012): são importantes para a recuperação da informação, em relação a contextos terminológicos, informacionais e linguísticos.

Repito que se trata de um disparador de inquietações, de um mobilizador de incômodos, com base em dados produzidos a partir de elementos tangíveis (ou seja: que são acessíveis a todos, independentemente de suas opções intelectuais e políticas), para que reflitamos conjuntamente como campo em constituição - e não de uma interpelação pessoal a nenhum dos estudiosos individualmente; isso porque, em chave materialista histórica e dialética, fica evidente tanto a natureza social do ser humano, quanto também o desenvolvimento psíquico (articulado diretamente à apropriação e elaboração do conhecimento) como resultado do processo de apropriação de signos culturais, dentre os quais, aqueles partilhados por uma dada comunidade científica, no caso, aquela da qual fazemos parte. Nosso intuito foi, a partir desse levantamento, perguntar a nós coletivamente, como campo, quanta atenção temos (ou não) dispensado à democracia e à pobreza nos estudos mais avançados que temos realizado ou orientado.

Assim, as palavras-chave foram definidas tendo em vista contemplar simultaneamente e de modo equilibrado dimensões individuais e coletivas da existência que independem tanto da Educação quanto da Literatura, mas que atravessam a realidade constitutiva dos esforços de ambos os campos. Procuramos, também, selecionar palavras-chave que, em seu conjunto, permitissem uma superação da polarização ou dicotomização que, muito frequentemente, ocorre, ao se tomar partido por correntes teórico-metodológicas que ora pretendem pôr em evidência a dimensão singular, ora a universal - o que costuma acontecer sem atentar à mediação da particularidade (LUKÁCS, 1966).

Em cada uma das teses, foram localizadas as ocorrências das seguintes palavras (e seus cognatos): coletiv[idade]; democra[cia]; desigual[dade]; individual[idade]; particular[idade]; pobre[za]; singul[aridade]; subjetiv[idade]; transforma[ção]; e violên[cia] - supondo que esse conjunto (como conjunto, e não individualmente) de ocorrências poderia nos indiciar tendências temáticas e, assim, mobilizar uma posterior problematização com relação ao fato de estarmos abordando o real pesquisado de maneira parcial ou em sua totalidade. A síntese quantitativa das ocorrências - a partir das quais encaminhamos análises qualitativas - pode ser vislumbrada na tabela abaixo: 
Tabela 1 - Ocorrências dos termos-chave para o estudo ${ }^{9}$

\begin{tabular}{|l|l|l|l|l|l|l|l|l|l|l|}
\hline Referência & $\begin{array}{l}\text { Colet } \\
\text { iv... }\end{array}$ & $\begin{array}{l}\text { Dem } \\
\text { ocra. } \\
. .\end{array}$ & $\begin{array}{l}\text { Desi } \\
\text { gual. } \\
. .\end{array}$ & $\begin{array}{l}\text { Indiv } \\
\text { idual } \\
\ldots\end{array}$ & $\begin{array}{l}\text { Parti } \\
\text { cular } \\
\ldots\end{array}$ & $\begin{array}{l}\text { Pobr } \\
\text { e... }\end{array}$ & $\begin{array}{l}\text { Sing } \\
\text { ul... }\end{array}$ & $\begin{array}{l}\text { Subj } \\
\text { etiv.... }\end{array}$ & $\begin{array}{l}\text { Tran } \\
\text { sfor } \\
\text { ma... }\end{array}$ & $\begin{array}{l}\text { Violê } \\
\text { n... }\end{array}$ \\
\hline BATISTA, 2017 & 16 & 6 & 5 & 16 & 18 & 5 & 7 & 5 & 24 & 9 \\
\hline $\begin{array}{l}\text { CAMASMIE, } \\
2017\end{array}$ & 27 & 0 & 28 & 35 & 33 & 3 & 15 & 36 & 53 & 1 \\
\hline $\begin{array}{l}\text { CAVALCANTE, } \\
2018\end{array}$ & 6 & 12 & 5 & 10 & 14 & 2 & 1 & 2 & 14 & 2 \\
\hline QUEIROZ, 2017 & {$[141]$} & 0 & 32 & 47 & 19 & 23 & 16 & 21 & 46 & 44 \\
\hline SANTOS, 2017 & 16 & 8 & 1 & 9 & 15 & 6 & 3 & 5 & 30 & 0 \\
\hline $\begin{array}{l}\text { SPENGLER, } \\
\text { 2017 }\end{array}$ & 1 & 6 & 0 & 3 & 2 & 0 & 8 & 10 & 6 & 0 \\
\hline TOTAIS & $\begin{array}{l}207 \\
{[66]}\end{array}$ & 32 & 71 & 120 & 101 & 39 & 50 & 79 & 173 & 56 \\
\hline
\end{tabular}

Fonte: <https://catalogodeteses.capes.gov.br/catalogo-teses/>. Acesso em 06 de mai. 2019.

Salta aos olhos nesse conjunto de dados:

1) a alta frequência dos termos-chave "transform[ação]" (com 173 ocorrências) e "coletiv[idade]" (com 207 ocorrências), despontando como os termos mais frequentes entre aqueles constantes na Tabela 1. Todavia, é preciso lembrar que este último termo precisa ser pensado face à situação de uma das teses discutir justamente os coletivos de poesia, constituídos em espaços periféricos. Se fossem descontadas as ocorrências localizadas no trabalho de Queiroz (2017), sobrariam apenas 66 ocorrências do termo "coletiv[idade]";

2) a altíssima ocorrência de “individual[mente]" (com 120 ocorrências), "particular[mente]" (com 101 ocorrências) e "subjetiva[mente]" (com 79 ocorrências). É preciso considerar que o termo "particular[mente]" pode ser usado, textualmente, para um sentido que não enfatize os particularismos, mas para fazer referências coesivas; porém, na análise contextualizada dos termos, ficou patente que a ambiência semântica majoritária é aquela que trata da particularidade de cada leitor;

3) os termos menos frequentes, a partir dos dados da Tabela 1, são "democra[cia]" (com 32 ocorrências) e "pobre[za]" (com 39 ocorrências). Ou seja, a democracia, a democratização e a discussão sobre o que é ou não democrático são as ocorrências menos frequentes, ao lado da pouca atenção aos pobres e à pobreza. Ao lado disso, é significativo que o campo em constituição não esteja discutindo enfaticamente a "violên[cia]" - que, em geral, está justamente

\footnotetext{
${ }^{9}$ Arquivos digitais das teses disponibilizados a partir de sua localização no Catálogo de Teses e Dissertações da Capes. A busca foi atualizada até o dia 06 de maio de 2019, às 9h da manhã. Quadro organizado pela autora.
} 
relacionada à falta de acesso a condições materiais dignas e ao reconhecimento e efetividade dos direitos da cidadania, como prerrogativa da experiência democrática.

Obviamente, as palavras buscadas no interior dos documentos e quantificadas em dados numéricos, sem uma análise contextual ocorrência a ocorrência, estão sujeitas a distorções. Não podemos ignorar, igualmente, os riscos do "quantitavismo" na simplificação redutora de fazer pressupor uma equivalência entre os temas e perspectivas e o uso ou não de certas palavras. Porém, os dados sistematizados na Tabela 1, a partir dos arquivos digitais do corpus apresentado no Quadro 1, são tomados, aqui, como um indício, a ser cotejado com inúmeros outros, em pesquisas e reflexões futuras.

A partir desse conjunto de dados, fica a questão: se a pobreza e a democracia são questões proporcionalmente pouco presentes em nossos estudos mais avançados, o que temos pautado e desde que perspectiva? A quem e a que isso tem interessado? Qual é nossa responsabilidade e quais são os nossos desafios?

\section{Considerações finais}

Como pontuado ao longo do texto, as conclusões parciais deste estudo são as seguintes: há uma concentração no Sul e no Sudeste das instituições em que as teses foram desenvolvidas; os trabalhos possuem uma extensão média significativa, o que faz pressupor um desenvolvimento alentado das informações e análises; há uma grande diversidade de temas e de níveis e modalidade de educação contemplados; e as ocorrências de termos-chave para este estudo menos presentes quantitativamente no conjunto de teses é, justamente, da "pobre[za]" e da "democra[cia]".

Feitas essas constatações, partimos a uma dimensão ensaística que visa a convocar ao campo a uma reflexão conjunta, pois, antes de pôr em questão aspectos atinentes a qualquer disciplina ou campo do conhecimento, talvez seja preciso perguntar e responder: Que sociedade temos? Que sociedade queremos? O que exigiria ainda outras indagações articuladas: Como faremos as travessias entre a sociedade que temos e a que queremos? De que sujeitos humanos precisaremos neste processo? Qual é o papel do professor e das escolas (e aqui, em "escolas", incluem-se também os centros de ensino superior e as universidades) no processo de formação desses sujeitos?

Essa interpelação sobre as escolas se dá porque, de dentro das tradições pedagógicas críticas, que têm em vista um horizonte histórico, tais instituições são, desde a Modernidade, constituídas a partir do Estado burguês preservando em seu cerne uma tensão contraditória 
constitutiva, visto que, simultaneamente, operam na reprodução social e dão acesso à parcela mais pobre da população a alguma possibilidade de democratização do saber e instrumentalização para a compreensão e superação da própria condição social (SAVIANI, 2008, 2007, 2003).

Ao mesmo tempo que têm forte papel de controle e docilização, as escolas são socialmente designadas para se incumbirem dos processos de ensino-aprendizagem e, assim, da transmissão crítica e devidamente contextualizada de conhecimentos, procedimentos e atitudes nos diferentes campos do saber e das práticas humanas. Ou seja, as escolas são convocadas a confirmar em cada homem a sua humanidade, pela via da transformação qualitativa exercida sobre seu psiquismo, por meio da apropriação e objetivação dos conhecimentos, procedimentos e atitudes historicamente relevantes produzidos e transmitidos pelo conjunto dos homens e mulheres no processo histórico (MARTINS, 2013), além, é claro, de viabilizarem para parte da população normalmente alijada ou espoliada dos bens culturais coletivos alguma possibilidade de forjar uma individualidade para si (DUARTE, 2013), pela superação da alienação em direção ao processo humanizador requerido e produzido no processo educacional.

As escolas fazem isso satisfatoriamente? A resposta não é fácil. Levando-se em conta apenas dados estatísticos, tenderíamos a responder que não. Mas cá estamos: muitos de nós nascidos em famílias pobres, com pais semiescolarizados ou mesmo analfabetos, tendo vivido no campo ou nas periferias urbanas violentadas cotidianamente de todas as formas, estudado em escolas públicas precárias, realizado nossos estudos pós-graduados com bolsas de pesquisa aviltantes e, às vezes, conciliando exaustivas jornadas com a leitura de centenas de páginas difíceis... com tudo isso, a escola conseguiu que sejamos capazes de compreender (e ensinar a compreender) os textos e procedimentos literários que consideramos fundamentais, e, pela via da escolarização (básica e universitária), temos nos constituído como pesquisadores neste campo de pesquisa em desenvolvimento.

Doravante, faz-se necessário retomar a ideia de fetichização, em diálogo com as ideias organizadas em Duarte (2012). Etimologicamente, o termo reporta a "feitiço", a objeto produzido pelo homem ou pela natureza ao qual se atribuem poderes e se presta culto. $\mathrm{O}$ fetichismo, portanto, é, em suas origens, um fenômeno de ordem religiosa. Como recobra Duarte (2012), não à toa Marx argumentou que a crítica ao modo religioso vulgar de pensar e produzir o mundo não deveria ser o ponto de chegada, mas de partida no processo de 
desfetichização social - ou seja, não é bastante combater as ilusões no plano das consciências, é preciso modificar a realidade social que faz com que as pessoas não possam prescindir delas.

As crescentes ondas de negação e combate ao pensamento elaborado passível de comunicação e debate amplo com direito ao contraditório - seja esse conhecimento científico, artístico ou filosófico - é uma evidência de que não podemos ignorar de possível fetichização em nossa realidade social. O ódio aos intelectuais, às universidades e a tudo o que representam (TIBURI, CASARA, 2016) é um risco também para um campo de pesquisa emergente. E, nesse sentido, um campo em constituição como o nosso (Educação Literária), caso ignore as condições concretas em que o processo de formação humana se dá em nossas sociedades (ameaçadas pela crescente desigualdade e pela retração democrática), contribui para a perpetuação de condições que tornam o fetiche uma necessidade.

Desde Bakhtin (2003, 1988), pelo menos, sabemos que os textos literários são produzidos, publicados e circulam em razão de necessidades dialeticamente individuais e sociais no processo histórico. Sejam necessidades de ordem artística (por exemplo, questionar formas estéticas, técnicas, materiais e recursos até então prestigiados), sejam necessidades expressivas, sejam necessidades reflexivas (por exemplo, pensar os modos de vida e as relação humanas e a condição dos sujeitos no bojo desses modos e relações), sejam necessidades evasivas e lúdicas - todas elas atravessadas pela necessidade humana de posicionamento volitivo e axiológico no mundo

Por isso, tanto o processo de criação quanto o processo de recepção têm como fundamento a comunicação intersubjetiva - e a produção de sentidos exige a negociação, no mínimo, entre: a) a "letra dura" do texto e sua discursividade; b) o valor social das diferentes formas materiais de publicação; c) a posição social do enunciador e das diferentes vozes nos contextos de enunciação, publicação e circulação; d) as posições ideológicas (volitivas e axiológicas) inerentes a todo discurso situado e que viabilizam, constrangem ou induzem a certos modos de ler e à produção de certos sentidos em detrimento de outros.

Para haver comunicação intersubjetiva, para além de uma linguagem comum, é necessário haver, então, um corpo de conhecimentos, procedimentos e atitudes partilhados, a cada momento histórico: sejam os de ordem científica/metalinguística (no nosso campo, atinentes aos Estudos Linguísticos, Literários e Tradutológicos), sejam os de ordem procedimental (por exemplo, os modos de se inserir em um debate acadêmico, de organizar um slam poético), sejam os de ordem atitudinal (por exemplo, que é aceitável, a apropriação, a paródia, o pastiche, mas não o plágio). Quem assegurará isso à parcela mais pobre de nossa 
sociedade? Não vejo outra resposta que não seja o ensino-aprendizagem de Literatura - não exclusivamente, mas principalmente pela educação básica e superior. É essa transmissão que a escola precisa legar a cada uma das pessoas e ao conjunto da sociedade no caso da Literatura. É a apropriação e objetivação desse repertório que propiciará a transformação qualitativa do psiquismo e, assim, permitirá que possamos, pela via educacional, com todas as suas idiossincrasias, educar os sujeitos humanos necessários à transformação da sociedade que temos em direção à sociedade que queremos.

A (so)negação, na escola, de conteúdos escolares imediatamente reconhecíveis, comunicáveis e objetiváveis, o esvaziamento de um repertório de textos socialmente reconhecidos como clássicos e a insistência na impossibilidade de negociação social de sentidos para os textos tem como consequências: a impossibilidade de reproduzir em cada ser humano singular a humanidade genérica (DUARTE, 2013), o esvaziamento de um campo de conhecimentos, procedimentos e atitudes humanas e, enfim, a destruição de qualquer possibilidade democrática; pois a democracia necessita que saibamos negociar sentidos, produzir sentidos - e os textos literários, com sua plurissignificação e baixa literalidade, se lidos e discutidos intersubjetivamente com o propósito de debater posições enunciáveis e questionáveis, nos ensinam aquilo que é o fundamento do viver-com (e, portanto, do conviver).

A quem ou a que interessa que os pobres e a pobreza, bem como a desigualdade, neste país não sejam questões-chave no processo de constituição do campo da Educação Literária? A quem ou a que interessa que não tenham acesso ao que de mais elaborado a humanidade produziu em termos de conhecimento, procedimento e atitude literárias - debatendo, questionando e transformando isso, como forma de preparação para uma transformação social mais ampla e de mais radicais proporções?

O apagamento das condições materiais concretas da vida da maior parte da população em nossas pesquisas talvez, involuntariamente, esteja a participar da perpetuação de uma situação em que os seres humanos não se entendem como participantes de um rico caudal de relações nas quais têm o direito e o dever de se inserir ativamente para fazer as conquistas sociais civilizatórias e cidadãs não retrocederem.

Uma discussão consistente sobre a educação literária, que se atente à sua realidade coetânea, no âmbito da comunidade acadêmica requer, pois, um processo de desfetichização. E esse processo - que nunca é fácil - talvez possa ser iniciado com o exercício arriscado de olhar para nós mesmos, nosso lugar no mundo e o que estamos fazendo; por isso, o convite ao exercício meta-intelectual proposto neste trabalho, que constatou que a tematização da 
singularidade, da individualidade e da particularidade é muito mais recorrente que a da indagação pelos pobres, pela pobreza e pela democracia, na atualidade de um campo nascente de estudos no Brasil.

\section{Referências}

ANTUNES, B. O ensino da literatura hoje. Fronteiraz (São Paulo), v. 14, p. 3-17, 2015.

BAKHTIN, M. Estética da criação verbal. Trad. Paulo Bezerra. São Paulo: Martins Fontes, 2003.

BAKHTIN, M. Questões de literatura e de estética: a teoria do romance. [s. trad.]. São Paulo: Unesp; Hucitec, 1988.

BATISTA, J. D. A escrita literária e a Olimpíada de Língua Portuguesa "Escrevendo o Futuro": memórias de uma professora. 18/12/2017. 267 f. Tese de Doutorado (Letras). Universidade Federal do Espírito Santo, 2017.

BELO, R. Políticas públicas de incentivo ao livro, leitura e a literatura. Cadernos de Letras da UFF [online]. 2016, vol. 26, n. 52, pp. 183-203. DOI:

http://dx.doi.org/10.22409/cadletrasuff.2016n52a164. Disponível em: http://www.cadernosdeletras.uff.br/index.php/cadernosdeletras/article/view/164. Acesso em: 20 ago. 2019.

BORBA, D. dos S.; VAN DER LAAN, R. H.; CHINI, B. R. Palavras-chave: convergências e diferenciações entre a linguagem natural e a terminologia. Perspectivas em Ciência da Informação, v.17, n.2, p.26-36, abr./jun. 2012.

CAMASMIE, V. de A. Aulas de Literatura do Ensino Fundamental I do Colégio Pedro II - campus Humaitá. 08/12/2017. 249 f. Tese de Doutorado (Educação). Universidade Federal do Rio de Janeiro, 2017.

CANDIDO, A. O direito à literatura. In: . Vários escritos. 3. ed. revista e ampliada. São Paulo: Duas Cidades, 1995.

CAVALCANTE, R. de C. Práticas para educação literária: a formação docente na licenciatura em Letras em uma instituição pública do sul do Brasil. 30/01/2018. 158 f. Tese de Doutorado (Letras). Universidade Federal do Rio Grande do Sul, 2018.

DALVI, M. A. Escrever, imprimir, ler: objetos culturais e literatura. Vitória: Edufes, 2019.

DALVI, M. A. Políticas públicas para educação literária: nem públicas, nem literárias?. In: BRANDILEONE, A. P. F. N.; OLIVEIRA, V. da S. (Org.). Literatura na escola: contextos e práticas em sala de aula. Campinas: Pontes Editores, 2018a, pp. 23-38.

DALVI, M. A. Um clássico sobre Educação Literária: $O$ direito à literatura, de Antonio Candido. Estação Literária (Londrina), 2018b, v. 22, pp. 8-18. 
DALVI, M. A. Literaturas e infâncias: pesquisa (d)e pós-graduação como espaço político. Estudos de Literatura Brasileira Contemporânea (Brasília), 2015, n. 46, pp. 153-173.

DALVI, M. A. Literatura nos livros didáticos de ensino médio: as pesquisas de pósgraduação. Eutomia (Recife), 2013, v. 1, pp. 386-406.

DALVI, M. A.; REZENDE, N. L. de. Ensino de literatura: o que dizem as dissertações e teses recentes (2001-2010)?. DLCV (João Pessoa), 2012, v. 8, pp. 37-58.

DALVI, M. A. O perfil de professor que ingressa e que se forma no curso de Letras-Português na Universidade Federal do Espírito Santo. Signum: Estudos da Linguagem (Londrina), 2011, v. 14, pp. 173-193.

DALVI, M. A. et al. Uma notícia de pesquisa: a formação de professores no Espírito Santo em leitura, literatura e materiais didáticos. Revista Saberes Letras (Vitória), 2011, v. 9, pp. 445-465.

DIAS, A. C.; OLIVEIRA, M. F. A. P. de S. A formação do leitor literário na e pela universidade hoje: instantâneos de um subprojeto do PIBID. Contexto (Vitória), jan.-jun. 2015, n. 27, pp. 6-26.

DUARTE, N. A individualidade para si: contribuição a uma teoria histórico-crítica da formação do indivíduo (edição comemorativa). 3. Ed. Campinas: Autores Associados, 2013.

DUARTE, N. (Org.). Crítica ao fetichismo da individualidade. 2. Ed. revista. Campinas: Autores Associados, 2012.

ELISBON, E. P. M.; VALTÃO, R. de C. D. Entre a educação literária e a valorização da leitura no ensino médio: os (des)encontros dos documentos oficiais. Entreletras (Araguaína), v. 6 , n. 1, jan/jun. 2015, pp. 45-63.

GARCIA, C. A.; COUTINHO, L. G. Os novos rumos do individualismo e o desamparo do sujeito contemporâneo. Revista Psyche (São Paulo). v. 8, n. 13, jan.-jun. 2004, pp. 125-140. Disponível em: http://pepsic.bvsalud.org/scielo.php?script=sci_arttext\&pid=S141511382004000100011. Acesso em: 20 ago. 2019.

GINZBURG, J. O Ensino de Literatura como Fantasmagoria. Revista Anpoll (Florianópolis), 2012, v. 1, n. 33, [s. p.].

LUKÁCS, G. Estética: la peculiaridad de lo estético. v.1. Barcelona: Ediciones Grijalbo, 1966.

MARTINS, L. M. Desenvolvimento do Psiquismo e a Educação Escolar. Campinas: Autores Associados, 2013.

MARTINS, L. M.; ABRANTES, A. A.; FACCI, M. G. D. Periodização histórico-cultural do desenvolvimento psíquico. Campinas: Autores Associados, 2016. 
MORTATTI, M. do R. Na história do ensino da literatura no Brasil: problemas e possibilidades para o século XXI. Educar em Revista (Curitiba). n. 52, abr./jun. 2014, pp. 23-43.

NERI, M. A escalada da desigualdade: qual foi o impacto da crise sobre a distribuição de renda e a pobreza?. Rio de Janeiro: FGV Social, 2019. Disponível em:

https://cps.fgv.br/desigualdade. Acesso em 18 ago. 2019.

PEREZ-LINAN, A. Impeachment ou retrocesso? Ameaças à democracia no século XXI.

Revista Brasileira de Ciências Sociais [online]. 2018, vol. 33, n. 98. DOI:

http://dx.doi.org/10.1590/339801/2018.

QUEIROZ, H. A. A poesia em territórios improváveis: jovens de periferia em cena.

02/05/2017. 246 f. Tese de Doutorado (Educação). Universidade Federal do Rio de Janeiro, 2017.

ROSA, F. G. M. G.; ODDONE, N. Políticas públicas para o livro, leitura e biblioteca.

Ciência da Informação [online]. 2006, vol. 35, n. 3, pp.183-193. DOI:

http://dx.doi.org/10.1590/S0100-19652006000300017.

SALA, F. Políticas públicas do livro, leitura e biblioteca escolar no Brasil: das iniciativas federais à implementação municipal. Dissertação (Mestrado em Educação) - Universidade Estadual Paulista "Júlio de Mesquita Filho". Presidente Prudente, 2018.

SANTOS, O. M. S. dos. A Literatura e a escola: um estudo sobre modelos de educação literária no ensino médio em escolas públicas de Salvador (BA). 28/04/2017. 323 f. Tese de Doutorado (Educação). Universidade Estadual de Campinas, 2017.

SAVIANI, D. Escola e Democracia (edição comemorativa). Campinas: Autores Associados, 2008.

SAVIANI, D. Educação: do senso-comum à consciência filosófica. 17. Ed. Campinas: Autores Associados, 2007.

SAVIANI, D. Pedagogia histórico-crítica: primeiras aproximações. 10. Ed. Campinas: Autores Associados, 2003.

SILVA, A. P. D. da. O ensino de literatura hoje: da crise do conceito à noção de escritas. Campina Grande: EdUEPB, 2016.

SPENGLER, M. L. P. Alçando voos entre livros de imagens: o acervo do PNBE para a Educação Infantil. 22/03/2017. 213 f. Tese de Doutorado (Educação). Universidade Federal de Santa Catarina, 2017.

TIBURI, M.; CASARA, R. Ódio à inteligência: sobre o anti-intelectualismo. Revista Cult (São Paulo), out. 2016. Disponível em: https://revistacult.uol.com.br/home/50931-2/. Acesso em 24 ago. 2019. 
ZAMBRANO, G. O ensino de literatura brasileira nas escolas hoje. Literatura e Autoritarismo (Cascavel), 2015, n. 15, pp. 28-40, 2015. Disponível em:

http://cascavel.ufsm.br/revistas/ojs-2.2.2/index.php/LA/index. Acesso em: 24 ago. 2019.

Recebido em: 17/05/2020

Aceito para publicação em: 04/08/2020 